\title{
Patient considerations in the management of type 2 diabetes - critical appraisal of dapagliflozin
}

This article was published in the following Dove Press journal:

Patient Preference and Adherence

22 April 2014

Number of times this article has been viewed

\author{
Marissa C Salvo' \\ Amie D Brooks ${ }^{2}$ \\ Stacey M Thacker ${ }^{3}$ \\ 'Department of Pharmacy Practice, \\ University of Connecticut School of \\ Pharmacy, Storrs, CT, ${ }^{2}$ Department of \\ Pharmacy Practice, St Louis College of \\ Pharmacy, St Louis, MO, ${ }^{3}$ Department \\ of Pharmacy Practice, Southern \\ Illinois University Edwardsville, \\ Edwardsville, IL, USA
}

\begin{abstract}
Type 2 diabetes affects more than 350 million people worldwide, and its prevalence is increasing. Many patients with diabetes do not achieve and/or maintain glycemic targets, despite therapy implementation and escalation. Multiple therapeutic classes of agents are available for the treatment of type 2 diabetes, and the armamentarium has expanded significantly in the past decade. Selective sodium glucose co-transporter 2 inhibitors, including dapagliflozin, represent the latest development in pharmacologic treatment options for type 2 diabetes. This class has a unique mechanism of action, working by increasing glucose excretion in the urine. The insulin-independent mechanism results in decreased serum glucose, without hypoglycemia or weight gain. Dapagliflozin is a once-daily oral therapy. Expanding therapy options for a complex patient population is critical, and dapagliflozin has a distinct niche that can be a viable option for select patients with diabetes.
\end{abstract}

Keywords: SGLT2 inhibitor, selective sodium glucose co-transporter 2 inhibitors, pharmacological treatment

\section{Introduction}

Type 2 diabetes affects more than 350 million people worldwide, with increasing prevalence due to the aging population, increasing obesity rates, and greater representation of high-risk ethnic groups. ${ }^{1}$ The pathophysiology of diabetes is multifactorial, with elements of insulin resistance, insulin deficiency, progressive beta cell decline, and dysregulation of incretin hormones. The resultant hyperglycemia is a known contributor to multiple chronic complications, including cardiovascular disease, retinopathy, neuropathy, and nephropathy. Goals for glycemic indices have been established using clinical evidence, and endorsed by expert guidelines and position statements. Yet, these goals prove difficult to achieve and maintain in clinical practice. ${ }^{2-4}$ Evidence indicates that only about half of adult patients with type 2 diabetes achieve glycemic goals. ${ }^{5,6}$ For those patients who do reach the recommended hemoglobin $\mathrm{A}_{1 \mathrm{c}}\left(\mathrm{A}_{1 \mathrm{c}}\right)$ goal, control is lost at a rate of $5 \%-10 \%$ per year. ${ }^{7,8}$ Adequate management of the condition is complex, requiring a combination of lifestyle modifications and pharmacological therapy. ${ }^{3}$ The progressive nature of diabetes results in the need for more intensive approaches to glycemic control over time, and the majority of patients require multiple medications with complementary mechanisms of action. ${ }^{3}$

There are multiple therapeutic classes of agents available for the treatment of type 2 diabetes, and the armamentarium has expanded significantly in the past decade. Available therapeutic agents vary in mechanism, efficacy, safety, and route of administration. Metformin, one of the oldest therapeutic agents, works primarily by limiting hepatic glucose
Correspondence: Amie D Brooks Department of Pharmacy Practice, St Louis College of Pharmacy, 4588 Parkview Place, St Louis, MO 631 10, USA Tel + I 3 I 44468503

Fax +l 3144668500

Email amie.brooks@stlcop.edu 
production, via an increase in hepatic insulin sensitivity; it has a long record of clinical efficacy. As the most consistently recommended first-line agent, metformin is not without disadvantages. Although it is weight neutral, with a low risk of hypoglycemia, the risk of rare (but potentially fatal) lactic acidosis requires careful patient selection, avoiding those with renal insufficiency and unstable heart failure. ${ }^{3}$ Additionally, gastrointestinal side effects can limit its use for some patients. ${ }^{3}$ Insulin secretagogues, including sulfonylureas and meglitinides, have demonstrated clinical efficacy in the short term, but do not demonstrate durability over time. ${ }^{3}$ In addition, these work by stimulating endogenous insulin secretion. Thus, they carry a high risk of hypoglycemia, contribute to weight gain for most patients, and depend upon functional beta cells for efficacy. ${ }^{3}$ Thiazolidinediones increase insulin sensitivity in the periphery, and demonstrate clinical efficacy that is sustainable over time. ${ }^{9}$ Hypoglycemia is not common when they are used as monotherapy. However, fluid retention and weight gain limit their use, especially in combination with insulin, or in patients with heart failure. ${ }^{9}$ Alpha-glucosidase inhibitors delay the breakdown and absorption of glucose, thereby decreasing postprandial glucose following oral administration. ${ }^{10}$ This class requires multiple daily dosing, and slow dose titration is necessary to improve tolerability. ${ }^{10}$ Intolerable gastrointestinal side effects are common, and the overall efficacy of this class is minimal. Newer pharmacological classes include therapies that target incretin hormones, such as glucagon-like peptide-1 (GLP-1) agonists and dipeptidyl-peptidase-IV (DPP-IV) inhibitors. The GLP-1 agonists promote glucose-dependent insulin secretion, inhibition of inappropriate post-prandial glucagon secretion, and slowed gastric emptying. ${ }^{3}$ Available agents within this class are administered via subcutaneous injection, and range from twice-daily to once-weekly dosing frequency. Hypoglycemia is uncommon when they are used as monotherapy, and significant weight loss often results with continued use. ${ }^{11,12}$ Side effects common to this class include nausea, which is often limiting; pancreatitis and acute renal changes are emerging risks. ${ }^{11,12}$ A US Food and Drug Administration (FDA) boxed warning is in place for this class, due to the risk of medullary thyroid cancer, identified in animal studies; the class is contraindicated in patients with a personal or family history of medullary thyroid carcinoma. ${ }^{11,12}$ DPP-IV inhibitors block the enzyme responsible for degradation of endogenous GLP-1, thereby exerting a mechanism of action similar to GLP-1 agonists. ${ }^{3}$ Clinical efficacy is less robust than with direct GLP-1 agonists. However, this class is administered orally once-daily, which is often considered more desirable by patients. DPP-IV inhibitors are very well tolerated, with minimal hypoglycemia, and a potential for weight loss. ${ }^{3}$ Exogenous insulin therapies are the most effective pharmacological agents, with no dose limitations, and a mechanism that directly addresses insulin deficiency. ${ }^{3}$ Newer insulin analogues provide enhanced pharmacokinetic profiles that more closely mimic natural physiology, thereby minimizing hypoglycemia. Nonetheless, hypoglycemia remains a significant concern, and weight gain is a near certain result of dose titration. ${ }^{3}$

Evidence-based and expert consensus guidelines and position statements have been published in an effort to guide clinicians in patient-centered therapy selection, given the growing number of pharmacologic categories. The position statement of the American Diabetes Association and European Association for the Study of Diabetes endorses metformin as a first-line recommendation, followed by patient-specific selection for add-on therapy, considering clinical efficacy, risk of hypoglycemia, effects on weight, and cost. $^{3}$ The American Association of Clinical Endocrinologists, in 2013, also recommended a patient-centered approach to therapy selection, including metformin as an option for first-line therapy, but also including GLP-1 agonists, DPPIV inhibitors, and alpha-glucosidase inhibitors as alternate first-line options. ${ }^{4}$ Although the guideline recommendations differ in some specific instances, recognition of therapy limitations remains the same. Common side effects, such as hypoglycemia, weight gain, and gastrointestinal issues, as well as safety concerns over renal and/or hepatic dysfunction, limit the use or dose maximization of available medications. Additionally, the progressive nature of the disease necessitates additional therapies targeting the multifaceted pathophysiology. Selective sodium glucose co-transporter 2 (SGLT2) inhibitors, including dapagliflozin, represent the latest development in pharmacologic treatment options for type 2 diabetes. This class offers some unique advantages, when compared with other classes available, including low risks of hypoglycemia and weight gain, once-daily dosing, and a minimal side effect profile. Dapagliflozin is currently approved in Australia, Brazil, Mexico, New Zealand, the European Union, and the United States. ${ }^{13,14}$

\section{Pharmacology}

Healthy kidneys reabsorb nearly $99 \%$ of filtered plasma glucose, leaving only $1 \%$ to be excreted in the urine. ${ }^{15,16}$ Sodium glucose co-transporters (SGLTs) mediate this reabsorption. SGLT2 functions within the proximal convoluted tubule, and is responsible for approximately $90 \%$ of renal glucose reabsorption, while SGLT1 is expressed within 
the gastrointestinal tract, as well as the renal tubules, and is responsible for reabsorbing the remaining $10 \% .{ }^{17-19}$ In the setting of hyperglycemia (plasma glucose $>200 \mathrm{mg} / \mathrm{dL}$ ), the overall amount of glucose excreted in the urine is increased. However, the SGLTs become saturated, leading to inability of the kidneys to effectively sustain enough glucose excretion to maintain euglycemia. ${ }^{20}$ Inhibition of SGLT2 blocks sodium and glucose reabsorption, thereby increasing urinary glucose excretion, and decreasing plasma glucose concentration. ${ }^{21,22}$ The transport of sodium and glucose by the SGLT2 protein is driven by the sodium gradient between the proximal tubule and the tubular epithelial cells. ${ }^{19,21}$ Therefore, in addition to induction of glycosuria, additional fluid is excreted due to the reduction in sodium reabsorption. ${ }^{19,21}$

Because the mechanism of action is independent of insulin secretion, the SGLT2 class does not require functioning beta cells in order to be effective, and has limited risk of hypoglycemia and weight gain..$^{23,24}$ Dapagliflozin is a selective, competitive, reversible inhibitor of SGLT2. ${ }^{14}$ Selectivity for SGLT2 is an important advantage of the class, because SGLT1 is expressed to a greater extent in the gastrointestinal tract, and has demonstrated in animal studies an increased likelihood of gastrointestinal side effects, such as diarrhea and dehydration. ${ }^{25}$ Additionally, SGLT1 is responsible for only $10 \%$ of urinary glucose excretion, making it a less effective target for therapy. ${ }^{23}$

\section{Pharmacokinetics}

Taken orally, dapagliflozin has a bioavailability of $>75 \%$, and is rapidly absorbed into systemic circulation. ${ }^{26} \mathrm{~A}$ doseresponse relationship has been observed: glycosuria is induced after the initial dose; maximum plasma concentration is demonstrated within 2 hours. ${ }^{23}$ The mean elimination half-life is 12.9 hours, and dapagliflozin is $91 \%$ bound to plasma proteins. ${ }^{23}$ Metabolism to inactive metabolites occurs primarily via glucuronidation and, the cytochrome P450 (CYP) enzyme pathway is a minor clearance pathway. ${ }^{26}$ Elimination occurs primarily via renal excretion of inactive metabolites. ${ }^{14}$ Dapagliflozin does not induce or inhibit CYP isoenzymes. ${ }^{23}$ The pharmacokinetic profile of dapagliflozin is not significantly affected by age, sex, ethnicity, or the timing of administration. ${ }^{23}$

\section{Drug interactions}

Since the metabolism of dapagliflozin does not induce or inhibit CYP isoenzymes, there are minimal potential drug interactions. ${ }^{23}$ Pharmacokinetic analyses have been conducted, to include potential drug interactions with other common antidiabetic and cardiovascular agents. ${ }^{27,28}$ The first analysis found no concern, or need for dose adjustments, when used in combination with pioglitazone, metformin, glimepiride, or sitaglipitin. ${ }^{27}$ The second analysis expanded the list, to find no concerns with administering dapagliflozin in combination with simvastatin, valsartan, warfarin, or digoxin. ${ }^{28}$ The drugs assessed in the two analyses included a range of metabolic pathways.

Dapagliflozin may increase the risk of volume depletion, so its use with loop diuretics is not recommended. Additional caution is warranted for patients at risk for volume depletion and/or hypotension, such as those with acute illness, cardiovascular disease, concomitant antihypertensive therapy (especially thiazide diuretics), history of hypotension, and the elderly. Volume depletion may be more evident in patients with very high blood glucose levels. Careful monitoring of volume status and electrolytes is recommended when using dapagliflozin. ${ }^{26}$

\section{Efficacy}

Dapagliflozin is indicated for the treatment of type 2 diabetes as monotherapy, and as add-on therapy with many other antidiabetic agents. US prescribing information supports the combination of dapagliflozin with metformin, pioglitazone, glimepiride, sitagliptin (with or without metformin), and insulin (with or without other oral antidiabetic agents). ${ }^{14}$

Current European prescribing information does not recommend the combination of dapagliflozin and pioglitazone, as a precautionary measure, because studies are ongoing to evaluate pioglitazone and the risk of bladder cancer. ${ }^{26}$ Dapagliflozin has not been studied in combination with GLP-1 agonists. ${ }^{14,26}$ Phase III clinical trials, highlighting its use as monotherapy and add-on therapy, are summarized in Table 1.

Limited head-to-head studies have been performed with dapagliflozin. A 52-week randomized, multi-site, doubleblind, parallel-group, active controlled, non-inferiority study compared dapagliflozin with glipizide in patients inadequately controlled on metformin. The study included 814 patients who had $\mathrm{A}_{1 \mathrm{c}} 6.5 \%-10 \%$ while on metformin or metformin plus one additional oral antidiabetic medication (up to half-maximal dose). The study began with an 8-week period, when other antidiabetic agents were discontinued and patients were stabilized on metformin 1,500-2,000 mg/day. Level 1 of the study included randomization, in a 1:1 fashion, to dapagliflozin $2.5 \mathrm{mg}$ or glipizide $5 \mathrm{mg}$. Doses were titrated up to dapagliflozin $10 \mathrm{mg}$ and glipizide $20 \mathrm{mg}$, as tolerated. The primary endpoint resulted in statistical 
Table I Phase III clinical trials of dapagliflozin as monotherapy or add-on therapy

\begin{tabular}{|c|c|c|c|}
\hline Study & Methods & $\begin{array}{l}A_{I c} \text { reduction ( } \% \text { adjusted } \\
\text { mean change from baseline) }\end{array}$ & $\begin{array}{l}\text { Other statistically } \\
\text { significant }^{\mathrm{b}} \text { findings }\end{array}$ \\
\hline Dapagliflozin & 24-week, placebo-controlled RCT & AM 2.5 mg: not statistically significant & FPG reductions: \\
\hline \multirow[t]{8}{*}{ monotherapy ${ }^{29}$} & 485 treatment-naïve patients & AM $5 \mathrm{mg}:-0.77 \%(P<0.0005)$ & AM $2.5 \mathrm{mg}:-15.2 \mathrm{mg} / \mathrm{dL}$ \\
\hline & & AM I0 mg: $-0.89 \%(P<0.000 \mathrm{I})$ & AM 5 mg: $-24.1 \mathrm{mg} / \mathrm{dL}$ \\
\hline & & Placebo: $-0.23 \%$ & AM $10 \mathrm{mg}:-28.8 \mathrm{mg} / \mathrm{dL}$ \\
\hline & & PM doses had similar reductions & PM dose reductions ( -26 to $-30 \mathrm{mg} / \mathrm{dL}$ ) \\
\hline & & $(-0.79 \%$ to $-0.83 \%)$ (extrapolated data) & (extrapolated data) \\
\hline & & Patients with baseline $A_{l c} \geq 10 \%$ had & Patients with baseline $A_{I c} \geq 10 \%$ had \\
\hline & & mean change in $A_{I c}$ of $-2.88 \%$ (for $5 \mathrm{mg}$ ) & FPG reductions of -77 to $-84 \mathrm{mg} / \mathrm{dL}$ \\
\hline & & and $-2.66 \%$ (for $10 \mathrm{mg}$ ) (extrapolated data) & (extrapolated data) \\
\hline Dapagliflozin & 24-week, double-blind, & $5 \mathrm{mg}:-0.82 \%$ & FPG reductions \\
\hline \multirow[t]{5}{*}{ monotherapy ${ }^{30}$} & placebo-controlled RCT & $2.5 \mathrm{mg}:-0.72 \%$ & I mg: - | mg/dL \\
\hline & 282 treatment-naïve patients & I mg: $-0.68 \%$ & $2.5 \mathrm{mg}:-22 \mathrm{mg} / \mathrm{dL}$ \\
\hline & & Placebo: $0.02 \%(P<0.000 \mathrm{I}$, for all doses $)$ & $5 \mathrm{mg}:-28 \mathrm{mg} / \mathrm{dL}$ \\
\hline & & & OGTT reductions (with all doses): \\
\hline & & & -33 to $-52 \mathrm{mg} / \mathrm{dL}$ \\
\hline Dapagliflozin + & 24-week, double-blind, & $2.5 \mathrm{mg}:-0.65 \%(P=0.0008)$ & FPG reductions: \\
\hline metformin vs & placebo-controlled RCT & $5 \mathrm{mg}:-0.67 \%(P<0.000 \mathrm{I})$ & $5 \mathrm{mg}:-26 \mathrm{mg} / \mathrm{dL}$ \\
\hline placebo + & Extension study to 102 weeks & $10 \mathrm{mg}:-0.82 \%(P<0.000 \mathrm{I})$ & 10 mg: $-24 \mathrm{mg} / \mathrm{dL}$ \\
\hline metformin $^{31,32}$ & 546 patients inadequately & Placebo: $-0.31 \%$ & \\
\hline
\end{tabular}

FPG reductions: $10 \mathrm{mg}:-15 \mathrm{mg} / \mathrm{dL}$

metformin vs

placebo +

metformin $^{33}$

Dapagliflozin +

glimepiride vs

placebo +

glimepiride ${ }^{34}$

Dapagliflozin + insulin vs placebo + insulin ${ }^{35}$

Dapagliflozin + pioglitazone vs placebo + pioglitazone ${ }^{36}$

Dapagliflozin + sitagliptin vs placebo + sitagliptin ${ }^{37}$
546 patients inader monotherapy ( $\geq \mathrm{I}, 500 \mathrm{mg} /$ day $)$ 24-week double-blind, placebo-controlled RCT 182 patients inadequately controlled on metformin 24 week double-blind, placebo-controlled RCT 597 patients inadequately controlled on SU ( $\geq$ half the maximum recommended dose)

24-week, placebo-controlled RCT with blinded oral administration 808 patients inadequately controlled on insulin ( $\geq 30$ units/day) Mean daily insulin dose was 77. I units/day, with $17 \%$ using basal insulin and $83 \%$ using sliding-scale

24 week, placebo-controlled RCT 480 patients inadequately controlled on pioglitazone 30-45 mg/day

24-week, placebo-controlled RCT 45 I patients inadequately controlled on sitagliptin $100 \mathrm{mg} /$ day \pm metformin $\geq \mathrm{I}, 500 \mathrm{mg} /$ day
At 102 weeks, reductions were

maintained: $-0.48 \%$ to $-0.78 \%$

I0 mg: $-0.39 \%$

Placebo: $-0.10 \%(P<0.000 \mathrm{I})$

$2.5 \mathrm{mg}:-0.58 \%$

$5 \mathrm{mg}:-0.63 \%$

$10 \mathrm{mg}:-0.82 \%$

Placebo: $-0.13 \%$

$P<0.000$ I, for all doses

Hypoglycemic episodes were more

frequent in the dapagliflozin arm

(6.9\%-7.9\% vs $4.8 \%$ placebo)

$2.5 \mathrm{mg}:-0.79 \%$

$5 \mathrm{mg}:-0.89 \%$

I0 mg: $-0.96 \%$

Placebo: $-0.39 \%$

$P<0.000$ I, for all doses

After 48 weeks, $A_{\text {lc }}$ reduction was

maintained with all doses

$(-0.79 \%$ to $-1.01 \%)(P<0.001)$

Hypoglycemic episodes were $53.6 \%$ for dapagliflozin $10 \mathrm{mg}$ vs $51.8 \%$ with placebo

$5 \mathrm{mg}:-0.82 \%(P=0.0007)$

$10 \mathrm{mg}:-0.97 \%(P<0.0000 \mathrm{I})$

Placebo: $-0.42 \%$

After 48 weeks, $A_{\text {Ic }}$ reductions were maintained $(-0.95 \%$ to $-1.21 \%)$.

However, statistical tests were not performed

Without metformin: $10 \mathrm{mg}:-0.5 \%$

Placebo: $-0.1 \%(P<0.0001)$

With metformin: $10 \mathrm{mg}:-0.4 \%$

Placebo: $0.0 \%(P<0.000 \mathrm{I})$

Patients with baseline $A_{I c} \geq 8 \%$ had

mean change in $A_{I c}$ of $-0.8 \%$ compared

to $0.0 \%(P<0.000 \mathrm{I})$

Notes: ${ }^{\text {V} V e r s u s ~ p l a c e b o ; ~}{ }^{\text {bstatistical significance at } P<0.05}$

Abbreviations: $A_{1 c}$, hemoglobin $A_{1 c}$; RCT, randomized controlled trial; AM, morning; PM, evening; FPG, fasting plasma glucose; OGTT, oral glucose tolerance test; vs, versus; SU, sulfonylureas.

FPG reductions:

$5 \mathrm{mg}:-21 \mathrm{mg} / \mathrm{dL}$

$10 \mathrm{mg}:-28 \mathrm{mg} / \mathrm{dL}$

OGTT reductions

$(-32$ to $-35 \mathrm{mg} / \mathrm{dL})$ were statistically significant for $5 \mathrm{mg}$ and $10 \mathrm{mg}$

FPG reductions:

$2.5 \mathrm{mg}:-12 \mathrm{mg} / \mathrm{dL}$

$5 \mathrm{mg}:-20 \mathrm{mg} / \mathrm{dL}$

$10 \mathrm{mg}:-20 \mathrm{mg} / \mathrm{dL}$

At 48 weeks, FPG reduction was

-12 to $-17 \mathrm{mg} / \mathrm{dL}$

Patients continued usual daily dose of insulin with titrations, and up to two existing oral antidiabetic drugs ( $>50 \%$ on existing orals, mostly metformin) FPG reductions:

$5 \mathrm{mg}:-24.9 \mathrm{mg} / \mathrm{dL}$

$10 \mathrm{mg}:-29.6 \mathrm{mg} / \mathrm{dL}$

FPG reductions (combined \pm metformin)

I0 mg: -24.1 mg/dL

Placebo: $3.8 \mathrm{mg} / \mathrm{dL}$ 
non-inferiority, with both arms demonstrating an adjusted mean $\mathrm{A}_{1 \mathrm{c}}$ change of $-0.52 \%$ from baseline. Key secondary outcomes looked at change in total body weight (TBW), hypoglycemia episodes, and proportion of patients achieving a decrease of $\geq 5 \%$ of TBW. Hypoglycemic events occurred in $3.4 \%$ of the dapagliflozin group, compared with $39.7 \%$ of the glipizide group. There were no major hypoglycemic events (requiring external assistance, with blood glucose $<54 \mathrm{mg} / \mathrm{dL}$ ) in the dapagliflozin group, and only three episodes in the glipizide group. Minor hypoglycemia was defined as blood glucose $<63 \mathrm{mg} / \mathrm{dL}$. The absolute mean change in weight loss between the groups at week 52 was $-4.65 \mathrm{~kg}(P<0.0001)$, with $33.3 \%$ of dapagliflozin patients losing $\geq 5 \%$ of TBW, compared to $-2.5 \%$ of the patients in the glipizide group. Overall, glipizide had more hypoglycemic events and weight gain; whereas, dapagliflozin had more weight loss, urinary infections (10.8\% vs $6.4 \%$; $P<0.05$, in post-hoc analysis), and reduced renal function (5.9\% vs 3.4\%). The dapagliflozin group had one episode of acute renal failure, and 13 patients discontinued from the study due to decrease in estimated creatinine clearance (compared to 6 patients in the glipizide group). ${ }^{38}$

Another set of trials assessed initial treatment for patients with type 2 diabetes. Both were 24-weeks in length, doubleblind, active-controlled, randomized, controlled trials, comparing dapagliflozin, metformin XR, or both. Enrolled patients had an $\mathrm{A}_{1 \mathrm{c}}$ of $7.5 \%-12 \%$ and were treatment-naïve. Patients were randomly assigned in a 1:1:1 ratio to metformin XR monotherapy, dapagliflozin monotherapy, or combination therapy. Study 1 used dapagliflozin $5 \mathrm{mg}$, while Study 2 used dapagliflozin $10 \mathrm{mg}$. Metformin XR was titrated, as tolerated, up to 2,000 mg/day, in all arms of both studies. At 24 weeks, mean $A_{1 c}$ reductions from baseline were greater with combination therapy. Results from Study 1 included $\mathrm{A}_{1 \mathrm{c}}$ reductions as follows: dapagliflozin $5 \mathrm{mg}+$ metformin $(-2.05 \%)$ vs dapagliflozin $5 \mathrm{mg}(-1.19 \%)$ vs metformin monotherapy $(-1.35 \%)$. Results from Study 2 included the following $\mathrm{A}_{1 \mathrm{c}}$ reductions: dapagliflozin $10 \mathrm{mg}+$ metformin $(-1.98 \%)$ vs dapagliflozin $10 \mathrm{mg}(-1.45 \%)$ vs metformin monotherapy $(-1.44 \%)$. The $\mathrm{A}_{1 \mathrm{c}}$ reductions demonstrated for combination vs either agent monotherapy, in both studies, were statistically significant $(P<0.0001)$. Secondary endpoints included change in fasting blood glucose (FPG) at 24 weeks, proportion of patients achieving $\mathrm{A}_{1 \mathrm{c}}<7 \%$, $\mathrm{A}_{1 \mathrm{c}}$ in those with baseline $\geq 9 \%$, TBW, and the proportion of patients discontinued or failed. Study 2 also looked at non-inferiority and weight reduction. Fasting plasma glucose was lowest in the combination group, for both studies, compared to each agent alone $(P<0.0001)$. Both studies found more patients at $\mathrm{A}_{1 \mathrm{c}}$ goal $<7 \%$ in the combination group, compared with either agent alone $(P<0.05$, for each). In those patients with baseline $A_{1 c} \geq 9 \%$, combination therapy reduced $A_{1 c}$ by $-3.01 \%$ in Study 1, compared with $-1.67 \%$ for dapagliflozin $5 \mathrm{mg}(P<0.0001)$ and $-1.82 \%$ for metformin $(P<0.0001)$. Study 2 found $\mathrm{A}_{1 \mathrm{c}}$ reductions of $-2.59 \%$ in the combination group, $-2.14 \%$ for dapagliflozin $10 \mathrm{mg}(P=0.0133)$, and $-2.05 \%$ for metformin $(P=0.0036)$. Weight loss was statistically greater for dapagliflozin $10 \mathrm{mg}(P<0.0001$, compared with metformin) and combination therapy yielded more weight loss than metformin monotherapy in both studies $(P<0.0001)$. No major hypoglycemic events occurred, with seven mild events in Study 2 with combination therapy, compared to six events with metformin monotherapy. Dapagliflozin $10 \mathrm{mg}$ was found to be non-inferior to metformin at lowering $\mathrm{A}_{1 \mathrm{c}}$, and superior at lowering FPG $(P=0.0012) .{ }^{39}$

Additionally, on 24 September 2013, Bristol-Myers Squibb announced that new Phase III data showed significantly reduced $\mathrm{A}_{1 \mathrm{c}}$, compared with placebo, at 24 weeks, in patients inadequately controlled with metformin plus sulfonylurea. Results of this study were presented at the 49th Annual Meeting of the European Association for the Study of Diabetes, in Barcelona, Spain. Results revealed that patients treated with dapagliflozin $10 \mathrm{mg}$, in addition to metformin and a sulfonylurea, had a mean decrease in $\mathrm{A}_{1 \mathrm{c}}$ of $-0.86 \%$, compared with placebo $(-0.17 \%)(P<0.0001)$. This study has an ongoing 28 -week extension to continue efficacy and safety evaluations. ${ }^{40}$

Overall, Phase III studies have demonstrated the effectiveness of dapagliflozin as both monotherapy and add-on therapy. When used as monotherapy, dapagliflozin 5-10 mg lowered FPG (24-28 mg/dL) and reduced the plasma glucose following the 2-hour oral glucose tolerance test (OGTT) (33-52 mg/dL). ${ }^{29,30}$ When used as add-on therapy, dapagliflozin lowered FPG an additional 15-29 mg/dL, and reduced plasma glucose following the OGTT $(32-35 \mathrm{mg} / \mathrm{dL}) .{ }^{31-37}$ In treatment-naïve patients, dapagliflozin, combined with metformin, provided additional lowering of $\mathrm{A}_{1 \mathrm{c}}, \mathrm{FPG}$, and weight, compared with either agent alone. ${ }^{39}$ In patients inadequately controlled on metformin, dapagliflozin provided equal $\mathrm{A}_{1 \mathrm{c}}$ lowering to glipizide, with less hypoglycemia and weight gain. ${ }^{38}$ Dapagliflozin also provided additional $\mathrm{A}_{1 \mathrm{c}}$ lowering in patients already receiving metformin and sulfonylurea, or metformin and sitagliptin. ${ }^{37,40}$

Based on efficacy data, patients have another effective oral agent to consider in the treatment of their diabetes. Dapagliflozin can be considered as initial therapy in combination with metformin, or when metformin is not 
optimal. Due to dapagliflozin's unique mechanism of action, it also proves to be an effective add-on option to existing therapy, including metformin, sulfonylureas, DPP-IV inhibitors, pioglitazone, and insulin. Patients should expect to see reductions in $\mathrm{A}_{1 \mathrm{c}}, \mathrm{FPG}$, and OGTT. Although effectiveness is of utmost importance, it provides half of the consideration in the patient-centered approach to the treatment of diabetes. The remaining half is safety and tolerability.

\section{Safety and tolerability}

When considering drug therapy, side effect profiles assist in guiding patient-specific drug therapy selection, and this is no different for a patient's consideration of dapagliflozin. Dapagliflozin's unique mechanism results in numerous benefits, including increases in the excretion of glucose, sodium, and fluid, reduced plasma glucose, total caloric availability, and blood pressure. ${ }^{23,24,41}$ However, its use does not come without potential side effects.

Given its mechanism of action, dapagliflozin therapy results in increased urinary glucose excretion of 20.4-53.3 g/day, compared with placebo. However, no apparent changes in sodium, potassium, chloride, magnesium, or albumin were noted..$^{42}$ A clinically insignificant increase in blood urea nitrogen $(1.5-1.8 \mathrm{mg} / \mathrm{dL})$, compared with placebo $(0.3 \mathrm{mg} / \mathrm{dL})$, was noted at 24 weeks with dapagliflozin therapy. ${ }^{43}$ There was also a slight increase in serum creatinine, and a decrease in estimated glomerular filtration rate (eGFR), following initiation of therapy. However, both returned to baseline at 24 weeks. ${ }^{43}$

Dapagliflozin's efficacy is dependent upon renal function. Studies have shown that as renal function declines, so does the change in $\mathrm{A}_{1 \mathrm{c}}$. With an eGFR $>90 \mathrm{~mL} / \mathrm{min} / 1.73 \mathrm{~m}^{2}, \mathrm{~A}_{1 \mathrm{c}}$ decreased by $0.69 \%$ compared with $0.54 \%$, with an eGFR of 60-90 mL/min $/ 1.73 \mathrm{~m}^{2}$. A lesser decrease in $\mathrm{A}_{1 \mathrm{c}}(0.39 \%)$ was noted with an eGFR $<60 \mathrm{~mL} / \mathrm{min} / 1.73 \mathrm{~m}^{2} .{ }^{44}$ Thus, dose adjustment is not necessary for mild renal impairment (eGRF $>60 \mathrm{~mL} / \mathrm{min} / 1.73 \mathrm{~m}^{2}$ ). Initiation of therapy is not recommended in patients with an eGFR $<60 \mathrm{~mL} / \mathrm{min} / 1.73 \mathrm{~m}^{2}$. Furthermore, therapy should be discontinued if eGFR is persistently $<60 \mathrm{~mL} / \mathrm{min} / 1.73 \mathrm{~m}^{2}$. Baseline and ongoing assessment of renal function is recommended while taking dapagliflozin. ${ }^{14}$ Due to the increased risk of reduced renal function and volume depletion in the elderly (age $\geq 65$ years), caution is warranted when using dapagliflozin in these patient populations. $^{14}$

Studies including dapagliflozin therapy note genital and urinary tract infections for both men and women. The occurrence of genital myotic infections is $2 \%-13 \%$, with a mean of $7.9 \%$ and a standard deviation of $\pm 3.7 \%$, compared with placebo (up to $5 \%$ ). ${ }^{27,31,34,36,45,46}$ The common types of infections in women include vulvovaginal myotic infections, vaginal infection, vulvovaginal candidiasis, vulvovaginitis, genital infection, genital candidiasis, fungal genital infection, vulvitis, genitourinary tract infection, vulval abscess, and vaginitis bacterial. In men, they include balanitis, fungal genital infection, balanitis candida, genital candidiasis, genital infection male, penile infection, balanoposthitis, balanoposthitis infective, genital infection, and posthitis. Increased occurrence of genital mycotic infection was noted in women, and associated with the higher dose (10 mg) of dapagliflozin. ${ }^{14,29,31,34,38}$ The occurrence of signs and symptoms of a urinary tract infection (UTI) varied between dapagliflozin (mean: 5.6\%; standard deviation: $\pm 3.6 \%$ ) and placebo (up to $8 \%){ }^{29,31,34,36,45}$ Urinary tract infections include cystitis, Escherichia urinary tract infection, genitourinary tract infection, pyelonephritis, trigonitis, urethritis, kidney infection, and prostatitis. ${ }^{14,29,31,34,36,45}$ This is an important patient consideration in drug therapy selection, as recent findings indicate that adults with diabetes are more likely to experience a UTI $(9.4 \%)$ compared to those without diabetes (5.7\%). ${ }^{47}$

Since dapagliflozin does not cause insulin secretion, it has a lesser potential for hypoglycemia. When evaluating the final results of studies, fewer than $10 \%$ of individuals receiving dapagliflozin as monotherapy, or in combination with metformin, experienced hypoglycemia. ${ }^{29,31,39,45}$ No severe hypoglycemic events occurred-defined as symptomatic hypoglycemia with a plasma blood glucose $<54 \mathrm{mg} / \mathrm{dL}$, requiring third party assistance, or with confusion, disorientation, abnormal behavior, unconsciousness, or glucagon administration. ${ }^{31,39}$ When dapagliflozin was studied as add-on therapy with a sulfonylurea (glipizide), the occurrence of hypoglycemia was $6.9 \%-7.9 \%$, compared with $4.8 \%$ with monotherapy. ${ }^{34}$ In combination with insulin, the risk of hypoglycemia increases. In one study, dapagliflozin $10 \mathrm{mg}$, in combination with pre-study insulin use, resulted in nearly $30 \%$ of participants experiencing hypoglycemia. ${ }^{45}$ Caution should be exercised when using dapagliflozin in combination with medications known to increase the risk of hypoglycemia, such as insulin, glinides, and sulfonylureas. Prescribing information suggests lowering the dose of insulin, or medications known to cause insulin secretion, upon initiation of dapagliflozin therapy. ${ }^{14}$

In July 2011, the FDA Advisory Committee requested further investigation of dapagliflozin's risk-benefit profile, given an observed increase in the incidences of bladder and breast cancers. Bladder cancer occurred in 9 out of 5,478 patients treated with dapagliflozin, compared with 1 out of 3,136 control patients. ${ }^{43}$ Breast cancer occurred in 9 out 
of 2,223 patients treated with dapagliflozin, compared with 1 out of 1,053 control patients. ${ }^{43}$ However, 2-year carcinogenic studies in animals failed to demonstrate any pre-neoplastic or neoplastic activity. ${ }^{48}$ Another noteworthy concern is the occurrence of five cases of elevated aspartate transaminases (AST) or alanine transaminases (ALT), greater than three times the upper limit of normal levels found in dapagliflozin trials. Of the total, two could not be attributed to another cause, resulting in possible dapagliflozin-induced hepatic injury. ${ }^{43}$ Results of one study indicate dapagliflozin was well tolerated by individuals with mild and moderate hepatic impairment; while those with severe hepatic impairment experienced greater dapagliflozin exposure. Therefore, its use should be individualized in those with severe hepatic impairment, as its efficacy and safety profile have not been fully studied.$^{49}$ Given the current findings, dose adjustment is not necessary with mild or moderate hepatic impairment, and dapagliflozin should not be used in patients on dialysis. ${ }^{14,26,49}$

Given the diuretic effect of dapagliflozin, hypotension is a reported side effect. However, studies do not indicate significant hypotension or orthostatic hypotension, when compared with placebo. ${ }^{29,46}$ For some patients, blood pressure reduction may be a favorable side effect. Studies indicate a 2.1-6.4 $\mathrm{mmHg}$ and 1.7-3.3 $\mathrm{mmHg}$ reduction in systolic and diastolic blood pressure, respectively. ${ }^{29,42,45,46}$ Furthermore, an increase in urine volume and sodium excretion was noted within the first 2-3 days of initiating dapagliflozin. ${ }^{50}$ Assessment of volume status and correction is warranted prior to initiation of therapy. ${ }^{14}$

In addition to its $A_{1 c}$ and blood pressure lowering potential, dapagliflozin has other positive outcomes that make it a favorable choice for select patients with diabetes. Weight loss is noted in numerous dapagliflozin trials.

Table 2 Comparison of dapagliflozin and canagliflozin

\begin{tabular}{|c|c|c|}
\hline & Dapagliflozin $^{14}$ & Canagliflozin ${ }^{51}$ \\
\hline Approved indication & $\begin{array}{l}\text { Adjunct to diet and exercise to improve glycemic } \\
\text { control in adults with type } 2 \text { diabetes }\end{array}$ & $\begin{array}{l}\text { Adjunct to diet and exercise to improve glycemic } \\
\text { control in adults with type } 2 \text { diabetes }\end{array}$ \\
\hline Starting dose & $5 \mathrm{mg}$ once-daily in the morning & 100 mg once-daily \\
\hline Dose titration & May increase to $10 \mathrm{mg}$ for additional glycemic control & $\begin{array}{l}\text { May increase to } 300 \mathrm{mg} \text { with an eGFR } \geq 60 \mathrm{~mL} / \mathrm{min} / \\
\mathrm{I} .73 \mathrm{~m}^{2} \text {, for additional glycemic control }\end{array}$ \\
\hline$A_{\text {Ic }}$ reduction & $\begin{array}{l}\text { Monotherapy: }-0.8 \%(5 \mathrm{mg}) \text { and }-0.9 \%(10 \mathrm{mg}) \\
\text { With metformin: }-0.7 \%(5 \mathrm{mg}) \text { and }-0.8 \%(10 \mathrm{mg}) \\
\text { With glimepiride: }-0.6 \%(5 \mathrm{mg}) \text { and }-0.8 \%(10 \mathrm{mg}) \\
\text { With pioglitzone: }-0.8 \%(5 \mathrm{mg}) \text { and }-1.0 \%(10 \mathrm{mg}) \\
\text { With sitagliptin: NS (5 mg) and }-0.45 \%(10 \mathrm{mg})\end{array}$ & $\begin{array}{l}\text { Monotherapy: }-0.77 \%(100 \mathrm{mg}) \text { and }-\mathrm{I} .03 \%(300 \mathrm{mg}) \\
\text { With metformin: }-0.79 \%(100 \mathrm{mg}) \text { and }-0.94 \%(300 \mathrm{mg}) \\
\text { With sulfonylurea: }-0.70 \%(100 \mathrm{mg}) \text { and }-0.79 \%(300 \mathrm{mg})\end{array}$ \\
\hline Administration & With or without food & Before the first meal of the day \\
\hline Contraindications & $\begin{array}{l}\text { Hypersensitivity, severe renal impairment, } \\
\text { end stage renal disease, on dialysis }\end{array}$ & $\begin{array}{l}\text { Hypersensitivity, severe renal impairment, end stage } \\
\text { renal disease, on dialysis }\end{array}$ \\
\hline Warning and precautions & $\begin{array}{l}\text { Hypotension, increased serum creatinine, decrease } \\
\text { in eGFR, hypoglycemia with insulin and insulin } \\
\text { secretagogues, genital mycotic infections, } \\
\text { increase in LDL, bladder cancer }\end{array}$ & $\begin{array}{l}\text { Hypotension, increased serum creatinine, decrease } \\
\text { in eGFR, hyperkalemia, hypoglycemia with insulin } \\
\text { and insulin secretagogues, genital mycotic infections, } \\
\text { increase in LDL }\end{array}$ \\
\hline $\begin{array}{l}\text { Common side effects } \\
\text { ( } 5 \% \text { or greater incidence) }\end{array}$ & $\begin{array}{l}\text { Female genital mycotic infections, nasopharyngitis, } \\
\text { urinary tract infections }\end{array}$ & $\begin{array}{l}\text { Female genital mycotic infections, urinary tract } \\
\text { infections, increased urination }\end{array}$ \\
\hline Drug interactions (avoid use) & None reported & Pimozide \\
\hline $\begin{array}{l}\text { Drug interactions } \\
\text { (monitor concomitant use) }\end{array}$ & $\begin{array}{l}\text { May increase effect of hypoglycemia agents } \\
\text { and hypotensive agents }\end{array}$ & $\begin{array}{l}\text { Digoxin (increased } A \cup C \text { and } C_{\max } \text { ) } \\
\text { UGT enzyme inducers* (decrease AUC of canagliflozin) }\end{array}$ \\
\hline Renal impairment & $\begin{array}{l}\text { Do not initiate if eGFR }<60 \mathrm{~mL} / \mathrm{min} / 1.73 \mathrm{~m}^{2} \\
\text { Discontinue if eGFR is persistently } \\
<60 \mathrm{~mL} / \mathrm{min} / 1.73 \mathrm{~m}^{2}\end{array}$ & $\begin{array}{l}\text { Do not initiate if eGFR }<45 \mathrm{~mL} / \mathrm{min} / 1.73 \mathrm{~m}^{2} \\
\text { Discontinue if eGFR falls below } 45 \mathrm{~mL} / \mathrm{min} / 1.73 \mathrm{~m}^{2} \\
100 \mathrm{mg} \text { daily is maximum dose with eGFR } \\
45-60 \mathrm{~mL} / \mathrm{min} / 1.73 \mathrm{~m}^{2}\end{array}$ \\
\hline Hepatic impairment & Assess risk: benefit with severe hepatic impairment & Not recommended with severe hepatic impairment \\
\hline Special populations & $\begin{array}{l}\text { Pregnancy category: } C \\
\text { Breastfeeding: unknown excretion in breast milk } \\
\text { Pediatrics: not studied } \\
\text { Geriatrics: higher incidence of ADRs; similar } \\
A_{\text {Ic }} \text { reduction compared to those }<65 \text { years old }\end{array}$ & $\begin{array}{l}\text { Pregnancy category: } C \\
\text { Breastfeeding: unknown excretion in breast milk } \\
\text { Pediatrics: not studied } \\
\text { Geriatrics: higher incidence of ADRs; less } A_{\mathrm{lc}} \\
\text { reduction compared to those }<65 \text { years old }\end{array}$ \\
\hline How supplied & $5 \mathrm{mg}$ and $10 \mathrm{mg}$ tablets & $100 \mathrm{mg}$ and $300 \mathrm{mg}$ tablets \\
\hline
\end{tabular}

Note: *Rifampin, phenytoin, phenobarbital, ritonavir.

Abbreviations: eGFR, estimated glomerular filtration rate; NS, not studied; LDL, low-density lipoprotein; AUC, area under the curve; $C_{\text {max }}$, peak drug concentration; UGT, UDP-glucuronosyltransferase; ADRs, adverse drug reactions. 
Treatment with dapagliflozin resulted in a weight loss of approximately $2-3 \mathrm{~kg}$, compared with a $\sim 1 \mathrm{~kg}$ loss with metformin or placebo after $12-24$ weeks of therapy. ${ }^{39,46}$ When dapagliflozin was used as add-on therapy with metformin, glimepiride, and insulin, a statistically significant weight loss occurred at 24 weeks, with mean changes of $-2.9 \mathrm{~kg},-2.3 \mathrm{~kg}$, and $-1.7 \mathrm{~kg}$, respectively. ${ }^{31,34,35}$ Weight loss was maintained at 48 weeks when combined with insulin, and at 102 weeks when combined with metformin. ${ }^{32,35}$ In a 24-week trial, dapagliflozin $10 \mathrm{mg}$, used in combination with pioglitazone (a medication known to increase the risk of weight gain), resulted in a $-0.14 \mathrm{~kg}$ weight loss, compared with a $1.64 \mathrm{~kg}$ weight gain with pioglitazone monotherapy. ${ }^{36}$

Patients treated with dapagliflozin also saw improvement in triglyceride levels, compared with placebo, with reductions of $-2.4 \%,-6.2 \%$, and $-2.1 \%$, respectively. ${ }^{31}$ Additionally, there was improvement of $1.8 \%-4.4 \%$ in high-density lipoprotein levels..$^{29,31,42}$ Future studies are needed to assess the benefits of dapagliflozin's weight and blood pressure reductions and lipid improvements, in light of cardiovascular events. According to the FDA's mandate, all new oral antidiabetic medications are required to demonstrate no increased risk in cardiovascular events. Data from clinical trials to date do not indicate any increased risk. However, further studies are needed. ${ }^{43}$

\section{Place in therapy - conclusion}

With an ever-growing demand for oral antidiabetic medications, dapagliflozin, acting through a unique mechanism, reduces blood glucose and provides a favorable tolerability profile. With recent FDA approval for its use as monotherapy and add-on therapy, dapagliflozin is now a second-in-class agent. Table 2 compares and contrasts dapagliflozin with canagliflozin. ${ }^{14,51}$ The occurrence of genital mycotic infections and urinary tract infections associated with SGLT2s may pose limitations for use. The risks should be considered for each patient when selecting drug therapy.

While an array of oral antidiabetic medications are available, few favorably impact on comorbidities such as obesity and hypertension, which are often found in patients with diabetes. Dapagliflozin's noted blood pressure reduction, weight loss, and low potential to cause hypoglycemia are advantageous, when compared with currently available oral medications. Long-term clinical trials and post-marketing studies are needed to further investigate dapagliflozin's cardiovascular profile, and its impact on morbidity and mortality.

It is critical to expand therapy options for a complex patient population. Dapagliflozin has a distinct niche that can be a viable option for select patients with diabetes.

\section{Acknowledgments}

Marissa C Salvo, PharmD, BCACP, is Assistant Clinical Professor of the Department of Pharmacy Practice (University of Connecticut School of Pharmacy); Amie D Brooks, PharmD, FCCP, BCPS, BCACP, is Associate Professor of Pharmacy Practice in the Department of Pharmacy Practice (St Louis College of Pharmacy); Stacey M Thacker, PharmD, BCPS, BC-ADM, is Clinical Assistant Professor of the Department of Pharmacy Practice (Southern Illinois University).

\section{Disclosure}

The authors have no conflicts of interest to declare in this work.

\section{References}

1. International Diabetes Federation. Diabetes: facts and figures [cited 2013 Nov 16]. Available from: http://www.idf.org/worlddiabetesday/ toolkit/gp/facts-figures.

2. American Diabetes Association. Standards of medical care in diabetes - 2013. Diabetes Care. 2013;36:S11-S66.

3. Inzucchi SE, Bergenstal RM, Buse JB, et al. Management of hyperglycemia in type 2 diabetes: a patient-centered approach: position statement of the American Diabetes Association (ADA) and the European Association for the Study of Diabetes (EASD). Diabetes Care. 2012;35(6):1334-1379.

4. American Association of Clinical Endocrinologists. AACE comprehensive diabetes management algorithm. Endocr Pract. 2013;19(2): 327-336.

5. Nichols GA, Kimes TM, Harp JB, Kou TD, Brodovicz KG. Glycemic response and attainment of $A_{1 c}$ goals following newly initiated insulin therapy for type 2 diabetes. Diabetes Care. 2012;35(3):495-497.

6. Ong KL, Cheung BM, Wong LY, et al. Prevalence, treatment, and control of diagnosed diabetes in the US. National Health and Nutrition Examination Survey. 1999-2004. Ann Epidemiol. 2008;18(3): 222-229.

7. United Kingdom Prospective Diabetes Study (UKPDS). 13: Relative efficacy of randomly allocated diet, sulphonylurea, insulin, or metformin in patients with newly diagnosed non-insulin dependent diabetes followed for three years. BMJ. 1995;310(6972):83-88.

8. UK prospective diabetes study 16 . Overview of 6 years' therapy of type II diabetes: a progressive disease. UK Prospective Diabetes Study Group. Diabetes. 1995;44(11):1249-1258.

9. Actos [package insert]. Deerfield, IL: Takeda Pharmaceutical; 2013.

10. Precose [package insert]. Wayne, NJ: Bayer Healthcare Pharmaceuticals; 2011.

11. Byetta [package insert]. San Diego, CA: Amylin Pharmaceutical; 2011.

12. Victoza [package insert]. Plainsboro, NJ: Novo Nordisk; 2013.

13. AstraZeneca, Bristol-Myers Squibb [press release]. US FDA acknowledges receipt of resubmission of the new drug application for investigational compound dapagliflozin for the treatment of type 2 diabetes [cited August 1, 2013]. MarketWatch The Wall Street Journal. July 25, 2013. Available from: http://www.marketwatch. $\mathrm{com}$ /story/us-fda-acknowledges-receipt-of-resubmission-of-the-newdrug-application-for-investigational-compound-dapagliflozin-for-thetreatment-of-type-2-diabetes-2013-07-25.

14. Farxiga [package insert]. Princeton, NJ: Bristol-Myers Squibb; 2014.

15. Moe OW, Baum M, Berry CA, Rector FC Jr. Renal transport of glucose, amino acids, sodium, chloride, and water. In: Brenner BM, editor. Brenner and Rector's the Kidney. Philadelphia: WB Saunders; 1996: 413-452. 
16. Deetjen $P$, von Baeyer H, Drexel H. Renal glucose transport. In: Seldin DW, Giebisch G, editors. Seldin and Giebisch's the Kidney, 2nd ed. NewYork: Raven Press; 1992:2873-2888.

17. Isaji M. Sodium-glucose cotransporter inhibitors for diabetes. Curr Opin Investig Drugs. 2007;8(4):285-292.

18. Jabbour SA, Goldstein BJ. Sodium glucose co-transporter 2 inhibitors: blocking renal tubular reabsorption of glucose to improve glycaemic control in patients with diabetes. Int J Clin Pract. 2008;62(8): 1279-1284.

19. Bakris GL, Fonseca VA, Sharma K, Wright EM. Renal sodium-glucose transport: role in diabetes mellitus and potential clinical implications. Kidney Int. 2009;75(12):1272-1277.

20. Chao EC, Henry RR. SGLT2 inhibition - a novel strategy for diabetes treatment. Nat Rev Drug Discov. 2010;9(7):551-559.

21. Neumiller J, White JR, Campbell RK. Sodium-glucose co-transport inhibitors: progress and therapeutic potential in type 2 diabetes mellitus. Drugs. 2010;70(4):377-385.

22. Abdul-Ghani MA, DeFronzo RA. Inhibition of renal glucose reabsorption: a novel strategy for achieving glucose control in type 2 diabetes mellitus. Endocr Pract. 2008;14(6):782-790.

23. Plosker GL. Dapagliflozin: a review of its use in type 2 diabetes mellitus. Drugs. 2012;72(17):2289-2312.

24. Vasilakou D, Karagiannis T, Athanasiadou E, et al. Sodium-glucose cotransporter 2 inhibitors for type 2 diabetes: a systematic review and meta-analysis. Ann Intern Med. 2013;159(4):262-274.

25. Ehrenkranz JR, Lewis NG, Kahn CR, Roth J. Phlorizin: a review. Diabetes Metab Res Rev. 2005;21(1):31-38.

26. Forxiga [prescribing information]. Available from: http://www.forxiga. eu/prescribing-information. Accessed November 16, 2013.

27. Kasichayanula S, Liu X, Shyu WC, et al. Lack of pharmacokinetic interaction between dapagliflozin, a novel sodium-glucose transporter 2 inhibitor, and metformin, pioglitazone, glimepiride, or sitagliptin in healthy subjects Diabetes Obes Metab. 2011;13:47-54.

28. Kasichayanula S, Chang M, Liu X, et al. Lack of pharmacokinetic interactions between dapagliflozin and simvastatin, valsartan, warfarin, or digoxin. Adv Ther. 2012;29(2):163-177.

29. Ferrannini E, Ramos SJ, Salsali A, Tang W, List JF. Dapagliflozin in monotherapy in type 2 diabetes patients with inadequate glycemic control by diet and exercise: a randomized, double-blind, placebo-controlled, phase 3 trial. Diabetes Care. 2010;33(10):2217-2224.

30. Bailey CJ, Iqbal N, T'joen C, List JF. Dapagliflozin monotherapy in drug-naïve patients with diabetes: a randomized-controlled trial of low-dose range. Diabetes Obes Metab. 2012;14(10):951-959.

31. Bailey CJ, Gross JL, Pieters A, Bastien A, List JF. Effect of dapagliflozin in patients with type 2 diabetes who have inadequate glycaemic control with metformin: a randomized, double-blind, placebo-controlled trial. Lancet. 2010;375(9733):2223-2233.

32. Bailey CJ, Gross JL, Hennicken D, et al. Dapagliflozin add-on to metformin in type 2 diabetes inadequately controlled with metformin: a randomized, double-blind, placebo-controlled 102-week trial. BMC Med. 2013;11:43.

33. Bolinder J, Ljunggren O, Kullberg J, et al. Effects of dapagliflozin on body weight, total fat mass, and regional adipose tissue distribution in patients with type 2 diabetes mellitus with inadequate glycemic control on metformin. J Clin Endocrinol Metab. 2012;97(3):1020-1031.

34. Strojek K, Yoon KH, Hruba V, et al. Effect of dapagliflozin in patients with type 2 diabetes who have inadequate glycaemic control with glimepiride: a randomized, 24-week, double-blind, placebo-controlled trial. Diabetes Obes Metab. 2011;13(10):928-938.

35. Wilding JP, Woo V, Soler N, et al. Long-term efficacy of dapagliflozin in patients with type 2 diabetes mellitus receiving high doses of insulin. Ann Intern Med. 2012;156(6):405-415.
36. Rosenstock J, Vico M, Wei L, Salsali A, List JF. Effects of dapagliflozin, an SGLT2 inhibitor, on $\mathrm{HbA}(1 \mathrm{c})$, body weight, and hypoglycemia risk in patients with type 2 diabetes inadequately controlled on pioglitazone monotherapy. Diabetes Care. 2012;35(7):1473-1478.

37. Jabbour SA, Hardy E, Sugg J, Parikh S. Dapagliflozin is effective as add-on therapy to sitagliptin with or without metformin: a 24 week, multicenter, randomized, double-blind, placebo-controlled study. Diabetes Care. January 15, 2014. [Epub ahead of print.]

38. Nauck MA, Del Prato S, Meier JJ, et al. Dapagliflozin versus glipizide as add-on therapy in patients with type 2 diabetes who have inadequate glycemic control with metformin: a randomized, 52-week, doubleblind, active-controlled noninferiority trial. Diabetes Care. 2011;34(9): 2015-2022.

39. Henry RR, Murray AV, Marmolejo MH, et al. Dapagliflozin, metformin $\mathrm{XR}$, or both: initial pharmacotherapy for type 2 diabetes, a randomised controlled trial. Int J Clin Pract. 2012;66(5):446-456.

40. Bristol-Myers Squibb [press release]. New phase III data showed dapagliflozin significantly reduced AbA1c compared to placebo at 24 weeks in patients with type 2 diabetes inadequately controlled with the combination of metformin plus sulfonylurea. Available from: http://news.bms. com/press-release/rd-news/new-phase-iii-data-showed-dapagliflozinsignificantly-reduced-hba1c-compared-p\&t=635156160653787526. Accessed September 25, 2013.

41. Vallon V, Sharma K. Sodium-glucose transport: role in diabetes mellitus and potential clinical implications. Curr Opin Nephrol Hypertens. 2010;19(5):425-431.

42. Komoroski B, Vachharajani N, Boulton D, et al. Dapagliflozin, a novel SGLT2 inhibitor, induces dose-dependent glycosuria in healthy subjects. Clin Pharmacol Ther. 2009;85(5):520-526.

43. US Food and Drug Administration. FDA briefing document: NDA 202293 dapagliflozin 5 and $10 \mathrm{mg}$. July 19, 2011. Available from: http://www.fda.gov/downloads/AdvisoryCommittees/CommitteesMeetingMaterials/Drugs/EndocrinologicandMetabolicDrugsAdvisor yCommittee/UCM262994.pdf. Accessed November 12, 2013.

44. Bristol-Myers Squibb, AstraZeneca. NDA 202293 dapagliflozin: Endocrinologic and Metabolic Advisory Committee background document. July 13, 2011. Available from: http://www.fda.gov/downloads/ advisorycommittees/committeesmeetingmaterials/drugs/endocrinologicandmetabolicdrugsadvisorycommittee/ucm378079.pdf. Accessed November 12, 2013.

45. Wilding JP, Norwood P, T'joen C, et al. A study of dapagliflozin in patients with type 2 diabetes receiving high doses of insulin plus insulin sensitizers: applicability of a novel insulin-independent treatment. Diabetes Care. 2009;32(9):1656-1662.

46. List JF, Woo V, Morales E, Tang W, Fiedorek FT. Sodium-glucose cotransport inhibition with dapagliflozin in type 2 diabetes. Diabetes Care. 2009;32(4):650-657.

47. Stein J. Urinary tract infections more common in diabetics. Renal and Urology News. July 8, 2013. Available from: http://www.renalandurologynews.com/urinary-tract-infections-more-common-in-diabetics/ article/302056. Accessed January 13, 2014.

48. Adul-Ghani MA, DeFronzo RA. Dapagliflozin for the treatment of type 2 diabetes. Expert Opin Pharmacother. 2013;14(12):1695-1703.

49. Kasichayanula S, Liu X, Zhang W, et al. Influence of hepatic impairment on the pharmacokinetics and safety profile of dapagliflozin: an open-label, parallel group, single-dose study. Clin Ther. 2011;33(11): 1798-1808.

50. Komoroski B, Vachharajani N, Feng Y, et al. Dapagliflozin, a novel, selective SGLT2 inhibitor, improved glycemic control over 2 weeks in patients with type 2 diabetes mellitus. Clin Pharmacol Ther. 2009;85(5): 513-519.

51. Invokana [package insert]. Titusville, NJ: Janssen Pharmaceuticals; 2014. 


\section{Publish your work in this journal}

Patient Preference and Adherence is an international, peer-reviewed, open access journal focusing on the growing importance of patient preference and adherence throughout the therapeutic continuum. Patient satisfaction, acceptability, quality of life, compliance, persistence and their role in developing new therapeutic modalities and compounds to

optimize clinical outcomes for existing disease states are major areas of interest. This journal has been accepted for indexing on PubMed Central. The manuscript management system is completely online and includes a very quick and fair peer-review system. Visit http://www.dovepress.com/ testimonials.php to read real quotes from published authors.

Submit your manuscript here: http://www.dovepress.com/patient-preference-and-adherence-journal 